\title{
Knowledge Structures of Entering Computer Networking Students and Their Instructors
}

\author{
Kristen E. DiCerbo \\ Cisco Learning Institute, Phoenix, AZ, USA
}

Kristen.DiCerbo@ciscolearning.org

\section{Executive Summary}

Students bring prior knowledge to their learning experiences. This prior knowledge is known to affect how students encode and later retrieve new information learned. Teachers and content developers can use information about students' prior knowledge to create more effective lessons and materials. In many content areas, particularly the sciences, there is extensive research about the conceptions and misconceptions students bring to the learning environment. This research has used tools ranging from instructor and student interviews to written assessments to identify these ideas. In addition, concept maps have been explored as a way to understand how students relate different concepts to each other. A difficulty with concept maps is that there are not good solutions for studying larger groups of students, but also maintaining the detail to see how specific concepts are related. One way to address this is with similarity ratings and the use of the Pathfinder network program.

Although there are some areas in which a large amount is known about students' knowledge, there is little understanding of either student or instructor knowledge in the field of computer networking. This paper is a preliminary attempt to explore the knowledge structures of students entering a computer networking class and their instructors using the Pathfinder network methodology.

The study participants consisted of 156 students and 12 teachers in 12 different classes, each at a different institution. All of the students were enrolled in the first course (Cisco Certified Networking Associate 1) in the Cisco Networking Academy Program. Students and instructors rated the similarity between pairs of words that represented concepts covered in the course prior to beginning instruction in the course. There were two different groups of words, one representing the course as a whole and one representing a specific chapter. The similarity ratings for these terms were submitted to Pathfinder network analysis, creating both average concept maps for students and instructors as well as measures of the similarity between the maps.

Analysis of the maps revealed an instructor map that corresponded to the OSI model, a model of networking. The corresponding student map indicated students did not have this conceptualization of how the theoretical layers of the model work. Instead, students tended to link things that

Material published as part of this publication, either on-line or in print, is copyrighted by the Informing Science Institute. Permission to make digital or paper copy of part or all of these works for personal or classroom use is granted without fee provided that the copies are not made or distributed for profit or commercial advantage AND that copies 1) bear this notice in full and 2) give the full citation on the first page. It is permissible to abstract these works so long as credit is given. To copy in all other cases or to republish or to post on a server or to redistribute to lists requires specific permission and payment of a fee. Contact Publisher@InformingScience.org to request redistribution permission. might generalize as equipment, and words that sounded similar. This linking of equipment was further demonstrated in the analysis of concepts from the chapter that introduces basic networking concepts. Whereas instructors exhibited an organization by network type (local or wide-area), the students displayed an equipment-centric organization. The instructor networks provide initial information about how experts organize 
knowledge in this relatively young field. By understanding some of the ways that students understand concepts prior to instruction, teachers should be better able to focus and tailor instruction.

Keywords: Computer networking, Pathfinder network, concept maps, knowledge structures, novices, experts

\section{Introduction}

Students come to their learning experiences with a variety of ideas gained from their previous experiences. The ideas, skills, and abilities that students bring with them are referred to as prior knowledge (Jonassen \& Gabrowski, 1993). Prior knowledge greatly affects how students understand, remember, and ultimately learn new information. As early as 1968, Ausubel noted, "the most important single factor influencing learning is what the learner already knows." As new information is presented, it is essential for it to be linked with information already known by the student, and it is these connections that will allow learners to access the new information later ( $\mathrm{J}$. R. Anderson, 1995). Because novices in a field by definition don't know the content in that field, they have little to which they can relate the things they're attempting to learn. In addition, students frequently don't make logical connections between new ideas and prior knowledge (HayesRoth \& Thorndyke, 1979).

In many cases the domain-specific ideas that students carry with them are mistaken (Bishop \& Anderson, 1990; Brown \& Van Lehn, 1980; Costu \& Ayas, 2005; Michael, 1998; Vosniadou \& Brewer, 1992). Science, in particular physics, is one area where these mistaken ideas have been extensively explored. For example, it is known that students often think that force must be continuously applied to an object in order for the object to remain in motion and that heavier objects fall faster (Halloun \& Hestenes, 1985a). Misconceptions like these can affect students' comprehension and memory of new material (Kendeou \& van den Broek, 2005). Among introductory statistics students, the number of misconceptions held is negatively correlated with their class achievement (Khazanov, 2006).

Information about misconceptions of students in a class can assist the teacher in planning instruction. Helping teachers to understand students' knowledge and thinking leads to using improved instructional strategies (Carpenter, Franke, Jacobs, Fennema, \& Empson, 1998; Cobb et al., 1991). Information about common misconceptions across groups of students can also assist instructional designers and content developers in creating materials that provide opportunities for students to challenge their existing misconceptions while linking new knowledge to existing knowledge.

\section{Identifying Misconceptions}

In order to use information about misconceptions to inform instructors and instructional designers, the misconceptions must be identified. There are several methods that have been explored to identify misconceptions among students, including instructor interviews, student interviews, and student assessments. Each of these has strengths and weaknesses with regard to the type of information they will produce, their ability to be used with large groups of students, and the amount of time and effort they take to complete.

Instructor interviews have been employed in the domains of statistics (Khazanov, 2006) and elementary students' physics knowledge (Pine, Messer, \& St. John, 2001) to successfully develop lists of common misconceptions. The strength of this approach is that experienced instructors have seen many students in many classes, allowing information about large groups of students to be obtained efficiently. The risk of this approach is that it does not get information directly from students, and instructor may miss or misinterpret students' difficulties. 
Others have used open-ended questions to elicit misconceptions from students (Costu \& Ayas, 2005). Boo \& Watson (2001) conducted interviews with students each year for three years to monitor their progression in eliminating fundamental misconceptions about chemical reactions. Others have used interviews, as a way to have students make predictions about outcomes of experiments. For example, Shaffer \& McBeath (2005) asked people to predict trajectories of fly balls and estimations of the highest points to demonstrate misconceptions about perspective. These approaches allow in-depth information to be gathered from students, but are time consuming and not easily used with large numbers of students. This is a good method to use in capturing misconceptions in a field. However, in the case of an individual instructor, conducting openended interviews with every student in a class is probably unrealistic. In addition, if instructional designers are designing content for a national or global audience, interview findings might need to be confirmed with a larger sample using another method.

Student interviews are often conducted either independently or in conjunction with written assessments to further clarify student misconceptions (e.g., Costu \& Ayas, 2005). The combination of an open-ended questionnaire and student interviews has been used to identify misconceptions regarding magnetic field theory among college students (Guisasola, Almudi, \& Zubimendi, 2004). Responses were analyzed resulting in four main categories of misconceptions. This approach led to highly useful information, but open-ended questionnaires would again be difficult and time consuming to transfer to large numbers of students.

In order to identify common misconceptions about physics, Halloun \& Hestenes (1985b) constructed a multiple choice test on which different answers related to different possible ways of theorizing about the problem. By administering this to over 400 students, they began to understand how common various ways of thinking were. Korner (2005) also examined patterns of incorrect answers on a multiple choice test, in this case to determine common misconceptions about hierarchical graphs.

Following the identification of common misconceptions, researchers often attempt to create an assessment to measure the extent to which students hold these misconceptions. The Force Concept Inventory (FCI) (Hestenes, Wells, \& Swackhamer, 1992) and Force and Motion Conceptual Evaluation (Thornton \& Sokoloff, 1998) both have been used in physics classes to measure whether students understand physics concepts that underlie the calculations. Sencar \& Eryilamaz (2004) used a Simple Electric Circuit Concept Test to assess students' misconceptions about electric circuits. Similarly, Taylor \& Kowalski (2004) use a psychological information questionnaire to assess misconceptions about psychology among introductory psychology students. Odom \& Barrow's (1995) Diffusion and Osmosis Diagnostic Test is used to assess misconceptions related to those topics. Similarly other intelligent tutoring systems seek to assess students' incoming knowledge to determine what content will be most beneficial (Mogharreban, 2004). Multiple choice tests have the advantage of being easy to administer to large groups of students. The tests are well-suited to identifying misconceptions related to a specific topic. However, in many cases, the reasons behind the wrong answer have to be assumed, and it is more difficult to assess misconceptions across a domain.

\section{Concept Maps}

Clearly, different methods of identification of misconceptions have different strengths and weaknesses. The methods above largely center on misconceptions related to specific topics. However, in reality students must learn not just concepts but how many different concepts fit together (Ausubel, 1968). Just as a student may understand how to do a calculation without understanding why, a student may understand one component of a domain without understanding how it fits in to the domain (Borgen \& Manu, 2002). In fact, students build mental models or representations of knowledge in a particular area. However, Resnick (1987) concluded that without explicit assis- 
tance in connecting ideas, people do not usually learn concepts simply by building up pieces of knowledge. In fact, they may come up with their own idiosyncratic understandings of how ideas relate to each other (Bransford, Brown, \& Codking, 2000). One way to visualize these models is through the use of concept maps.

Concept maps are visual representations of how concepts are related to each other. Each concept is a node, connected to other related concepts. The maps theoretically represent the knowledge structures of the person who is drawing them. Concept maps can be used as a learning strategy, an instructional strategy, a strategy for curriculum planning, and/or a means of assessment (Novak, 1990). For example, concept maps have been administered at particular intervals over a learning period to assess change in knowledge structures about electricity (D. Anderson, Lucas, Ginns, \& Dierking, 2000), middle school science (Kinchin, Hay, \& Adams, 2000), and university engineering (Walker \& King, 2002). The AssessToLearn system (Gouli, Gogoulou, \& Grigoriadou, 2003) used a three step process with concept mapping as a main component in order to 1) assess students' prior knowledge - activate knowledge, 2) promote knowledge construction, and 3) assess knowledge construction.

There have been a variety of methods created to score concept maps, including holistic scoring, density scoring (based on the number of nodes and links), and validity scoring (based on "correct" links), all with or without comparison to a master map (McClure, Sonek, \& Suen, 1999). Different researchers have also assigned different point values or weights to different map elements. There have been concerns expressed about the reliability of these scoring methods (RuizPrimo \& Shavelson, 1996), although others have reported acceptable interrater agreement (e.g., Rice, Ryan, \& Samson, 1998). It is clear that visual inspection of concept maps can lead to an understanding of students' misconceptions; one can see where there are links that should not be present and where there are not links that should be present. However, visual examination limits the number of students who can validly be studied. Most of the scoring mechanisms described above were designed in an effort to get an assessment score, not indicate areas of misconceptions, so they tend to produce a single score for a map. This is useful for assessment purposes, but does not provide enough information to compare maps.

One technique has emerged that may allow for both the investigation of large numbers of students and location of specific misconceptions - the use of numerical judgments of similarity or closeness among a set of concepts (Kraiger, Ford, \& Salas, 1993). These ratings can then be converted into concept maps and their structures assessed using procedures in the Pathfinder network program (Schvaneveldt, 1990). The Pathfinder network scaling algorithm generates a network representation of the structure of the similarity ratings submitted for analysis. This representation contains concepts represented by nodes and links between nodes to demonstrate relationships; this is essentially a concept map without labels on the links. Pathfinder computes the links by computing all paths between nodes and including a link between nodes only if it represents the strongest link, or most direct path, based on the similarity ratings. The resulting map can be compared to an expert/ instructor's map and a measure of similarity obtained based on the number of common links. In addition, ratings can be combined to produce "average" networks across individuals.

The Pathfinder technique has been used to represent knowledge in diverse domains, including: studies of team performance (Lim \& Klein, 2006), software requirements (Kudikyala \& Vaughn, 2005), flight training (Schvaneveldt, Beringer, \& Lamonica, 2001), and mental health (Ober \& Shenaut, 1999). This technique has been used to evaluate changes in conceptualization before and after instruction in evolution (d'Apollonia, Charles, \& Boyd, 2004), statistics (Geske, 2001), and police training (Braverman, 1997). Gonzalvo, Canas, and Bajo (1994) demonstrated that Pathfinder networks varied depending on whether they had studied a textbook. They combined the Pathfinder analysis with multidimensional scaling and found that the multidimensional scaling represented the global properties of networks and the Pathfinder networks captured the local con- 
ceptual relations. Pathfinder scores have been shown to predict self-efficacy (Davis, Curtis, \& Tschetter, 2003), achievement (Chen, 1997; Goldsmith, Johnson, \& Acton, 1991), and behavior (Gomez, Hadfield, \& Housner, 1996). Johnson, Goldsmith, and Teague (1994) suggest the predictive power of Pathfinder comes from its consideration of all of the possible links with a concept and its ultimate dichotomization into directly linked and indirectly linked concept pairs.

\section{Conceptions about Computer Networking}

Computer networks have grown exponentially, with over 1 billion people worldwide using the internet, a growth of over 200\% just from 2000 to 2006 (Internet World Stats, 2006). This has resulted in large growth in the need for people to design, implement, and maintain networks, and a concomitant increase in the numbers of students taking networking courses. To date, over 1.3 million students have completed the first class in the Cisco Certified Network Associate (CCNA) curriculum, in addition to the untracked numbers using other curricula.

Given these numbers, it seems important to begin to understand how students learn networking. In addition, it would be advantageous to understand the knowledge structures of networking experts. Unfortunately, there is almost no published research using any method addressing how students or experts think about networking. This paper is a preliminary investigation to determine whether the Pathfinder procedures can be used to determine how entering networking students and their instructors conceptualize the main ideas in computer networking.

\section{Method}

\section{Participants}

Twelve teachers at 12 different schools teaching the Cisco Networking Academy Program participated in the study. Six teachers taught in high schools and six taught in community or technical colleges. Teachers had previously indicated interest in participating in research on teaching and learning and volunteered for participation in response to an email solicitation describing the study. The instructors' experience in working on production networks ranged from never to more than five years, with a median of three years experience. They indicated their experience teaching in the Cisco Networking Academy program on a multiple choice question (Less than one year, one to two years, three to five years, and more then five years. No instructor selected less than one year and the most common response was three to five years.

A total of 156 students participated in the study. Class sizes ranged from 6 to 24 students with a median of 13 students. Students were asked to rate their knowledge about networking; $31 \%$ indicated they did not know much about networking, 50\% indicated that they knew a little about networking, $17 \%$ indicated they knew quite a bit about networking, and 2\% indicated they know a lot about networking. $87 \%$ of the students reported that they had never been employed in networking while $13 \%$ reported they had.

This research was completed in the context of the Cisco Networking Academy Program, a global program in which information technology is taught via a blended program with face-to-face classroom instruction, an online curriculum, and online assessments. Developed by educators and networking professionals, the Networking Academy Program delivers Web-based curriculum, hands-on labs, instructor training and support, and preparation for industry-standard certifications. Since being launched in 1997, the program has been taught in more than 10,000 academies in 50 U.S. states and over 145 countries with curriculum in nine different languages. For purposes of this initial study, participants all came from U.S. schools using the English curriculum. All classes were CCNA (Cisco Certified Network Associate) 1 classes, which is the first in a set of 4 
classes which prepare students to take the CCNA Certification exam, as well as to obtain networking jobs.

\section{Materials and Procedure}

The initial step in the study was to identify the salient terms to be rated. This was done via a review of the curriculum, including the stated objectives and important terms. Two separate lists were created: one for the chapter on Networking Fundamentals ( 7 items) and one as an overview entire semester course (8 items). These item lists are presented in Table 1.

Table 1. List of Rated Terms

\begin{tabular}{ll}
\hline Networking Fundamentals & Overview \\
\hline LAN & Router \\
Hub & Switch \\
Router & IP Addressing \\
Switch & Subnetting \\
WAN & Fiber Optic \\
Modem & UTP \\
DSL & Ethernet \\
& MAC Address
\end{tabular}

Instructors and students used a computer program to rate every possible pairwise combination of the terms on a 10 point relatedness scale $(1=$ unrelated; $10=$ highly related). The pairs were presented in random order for rating. Raters were instructed to give quick judgments of relatedness rather than lengthy, deliberate ones. Both instructors and students completed the ratings at the beginning of the course, prior to any instruction on the topics to be rated.

\section{Pathfinder procedure}

The Pathfinder network algorithm (Schvaneveldt, 1990) was used to generate a network representing each student and instructor's organization of knowledge. Two parameters ( $q$ and $r$ ) need to be determined in the Pathfinder program to generate networks. In this case, the parameters used to compute the network were set at $\mathrm{r}=$ infinity and $\mathrm{q}=\mathrm{n}-1$, where $\mathrm{n}$ refers to the number of terms in the data. The $\mathrm{r}$ parameter was chosen to match the ordinal properties of the data, and the q parameter was chosen in order to generate the sparsest network possible from the given data. These are the accepted settings for data of the type in this study (Gomez et al., 1996; Schvaneveldt, 1990). In general, links are made between concepts (nodes) when the similarity between those nodes is greater than or equal to the total similarity of any other path having no more than $\mathrm{q}$ links.

The Pathfinder program averaged the data of instructors and students to get consensus networks. These networks can then be compared to each other. The similarity between the two networks is computed as the number of links in common divided by uncommon links. (The number of uncommon links is the total number of links in both graphs minus the number of common links.) Two identical networks will yield a similarity of 1 and two networks that share no links will have a similarity of 0 . The Pathfinder program also determines the probability of obtaining the observed number of links in common or more by chance from the hypergeometric probability distribution. 
An example is provided here to further explain and demonstrate the procedure. If a Pathfinder network is created with 8 concepts, there are 28 possible links in the network $(\mathrm{N}=\mathrm{n}(\mathrm{n}-1) / 2=$ $8(7) / 2)$. Two people complete the ratings task. One person's ratings resulted in a network with 8 links, while the other resulted in a network with 7 links. Three of these links are common between the two raters' networks. The similarity is the number of common links divided by the number of uncommon links $(3 /(8+7-3)=0.25)$. On the scale from 0 to $1,0.25$ indicates the networks are not highly similar. To further investigate the similarity, Pathfinder computes the probability of having 3 common links by chance using the hypergeometric probability formula. This formula becomes computationally difficult because of all of the factorial calculations, however, the formula can be found in Gomez et al (1996). In this case, the probability that these two networks share three paths by chance is .31. Schevaneveldt (2007) suggests this can be used as a statistical test of similarity; in general we would want there to be less than a .05 probability of the networks sharing these paths by chance in order to say the two networks were statistically similar. This is basically a test in which the null hypothesis is that the two networks are different. If the probability of sharing links by chance is less than .05 , then the null hypothesis is rejected and we say the two networks are statistically similar. This is a different test than traditional hypothesis test in which the null hypothesis is that two groups of data are the same and rejecting the null hypothesis indicates they are significantly different.

In this study, given that we are comparing instructors to students prior to instruction, we would expect their networks to be different, therefore the similarity numbers should be low and the probabilities to be high. That is, any similarities in the networks are likely a result of chance. More information will likely be gained through the inspection of the networks themselves to determine where links are and are not present.

\section{Results}

\section{Course Overview}

The first group of words analyzed was a selection from over the entire course, rather than from a specific chapter. The instructor and student networks are displayed in Figures 1a and 1b, respectively. Note that the primary source of information is the presence or absence of links; spatial layouts and link lengths are determined arbitrarily and have no meaning. The two networks have 3 links in common and 11 not in common, for a similarity of .27 (closer to 0 (completely dissimilar) than 1 (identical)). There is a $22 \%$ chance that a network could have 3 out of 14 total links shared by chance. Given these results, we cannot reject the idea that the similarities between the networks are due to chance.

Interestingly, the instructors' network came out very linearly. However, the words are clearly organized based on the OSI model. The OSI model is an abstract model of networking that divides a networking system into seven "layers." The first layer is the physical layer, which represents all the electrical and physical specifications. Fiber optic and UTP cable are part of this layer. Layer 2 is the data link layer, which provides the means to transfer data on the network. The Ethernet is the best example of this and switches and MAC Addresses are also associated with this layer. Layer 3 is the network layer, which allows data of different lengths to move across networks. Routers, IP Addresses, and subnetting are all associated with this layer.

Examination of the students' network shows that they clearly lack this method of organizing their knowledge. Although formal knowledge of the OSI model would not be expected of incoming students, it is clear that do not have a general conceptual understanding of how these concepts relate to each other to make up a network. The students' network also identifies specific areas where students have made incorrect links. For example, MAC addresses are not closely related to 

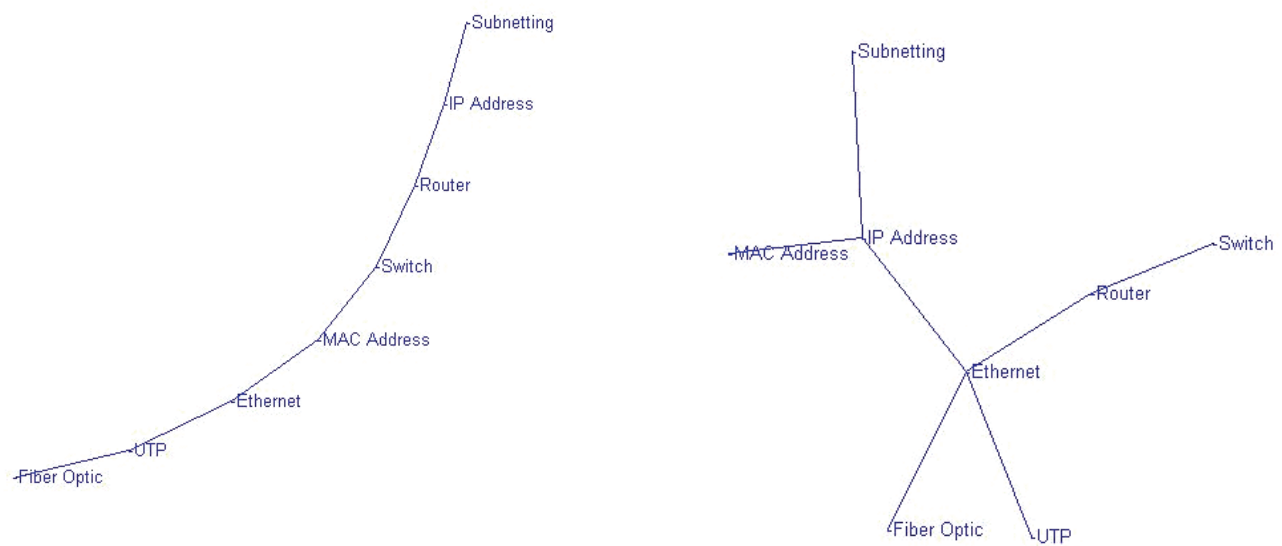

Figures 1(a) and (b). Instructor and Student Pathfinder networks of course overview

IP addresses. Students likely had not heard of one or both and linked them based on the fact that both had "address" in them. There should be links between IP addressing and routers and MAC addresses and switches. Finally, the Ethernet is more closely related to switches than to routers.

\section{Networking Fundamentals}

The second group of words analyzed covered concepts from a single chapter. The Networking Fundamentals chapter introduces basic networking concepts to students. The average instructor network is displayed in Figure 2a and the average student network is displayed in Figure $2 \mathrm{~b}$. The networks have 3 links in common and 13 not in common, for a similarity between the instructor and student networks of .23. The probability that they share this number of links by chance was .69 , indicating that any similarity between the networks is likely due to chance and the instructor and student networks are different from each other.
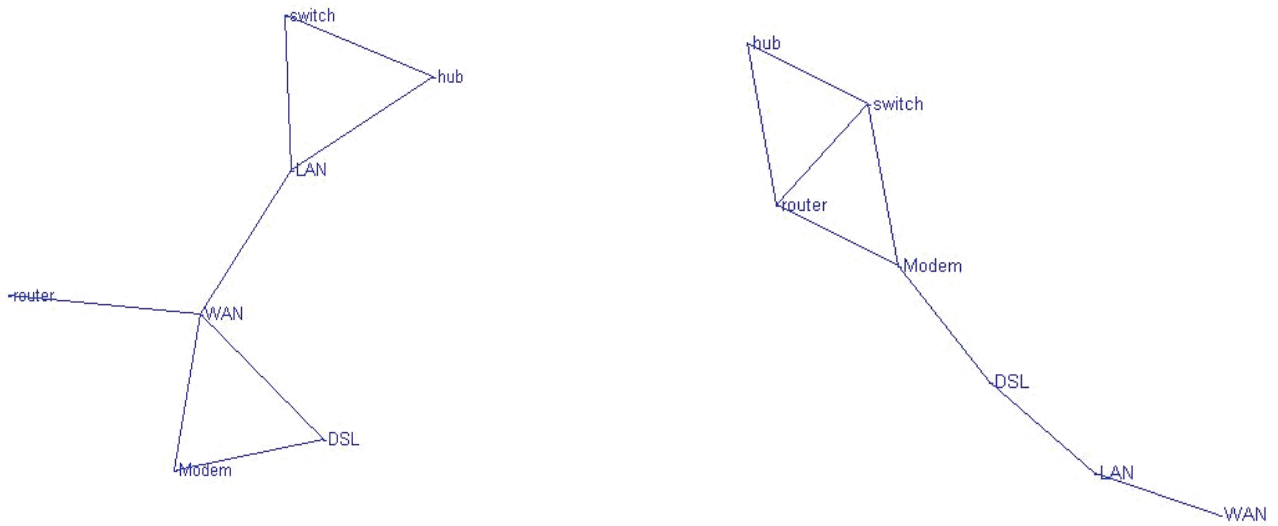

Figures 2(a) and (b). Instructor and Student Pathfinder networks of Fundamentals of Networking chapter

Visual examination of the networks indicates that the instructors' knowledge appears to be organized around the WAN and LAN, with the equipment associated with either as appropriate. This could be described as a "network-type centric" organization. The students, however, have a gen- 
eral grouping of all of the equipment in what could be called a "device centric" view. The connection between modem and DSL is not surprising, given this is likely more common consumer knowledge. The LAN and WAN terms are left hanging by themselves, with DSL connected to LAN, when it is probably better connected to WAN.

\section{Discussion}

The purpose of this study was to begin to explore the knowledge structures of students entering a computer networking class and their instructors. It also was a test of the utility of using the Pathfinder network methodology for eliciting student misconceptions. Analysis using a group of concepts covering the entire beginning networking course yielded an instructor map that corresponded to the OSI model. The corresponding student map indicated students did not have this conceptualization of how the theoretical layers of the model work. Instead, students tended to link things that might generalize as equipment, and words that sounded similar. This linking of equipment was further demonstrated in the analysis of concepts from the chapter that introduces basic networking concepts. Whereas instructors organize this around the type of network (local or wide-area) the students grouped all the equipment together in a device-centric organization. By understanding some of the ways that students understand concepts prior to instruction, teachers should be better able to focus and tailor instruction. Given the combination of student and instructor maps presented here, teachers can begin to visualize how their students understand (or don't understand) how networking concepts relate to each other, and formulate ways to begin to move them toward more advanced ways of understanding.

One note of caution is in order about the goal of using concept maps. It is not being suggested that all concept maps should look alike and the goal of instruction is to reproduce an instructors' concept map. In fact, most instructors differed in slight ways from the "average" map, often adding a link or two that the average map did not contain. The goal for students is to get closer to the instructor map, and not to endorse links that would commonly be accepted as incorrect by instructors or other experts.

\section{Limitations}

The findings in this study are limited by the words the participants were asked to rate. In some other studies employing Pathfinder methodology a larger number of words is used, however, every word added results in ratings of that word with every other word on the list. So, for example adding ninth word to an eight word list would create 8 more ratings to be done. Studies with larger numbers of words have asked participants to spend up to an hour completing the ratings task. Previous research with this population suggested that was too much time to ask, and it was likely that participants would begin to lose interest in the task and ratings would be less valid.

Another limitation is that all of the instructors in this research teach using the same curriculum. It may be that some of their conceptualizations of networking are related to the particulars of the curriculum. This may reduce the generalizability of these findings to other instructors or experts. For example, the OSI model is heavily emphasized in the curriculum, it may be that this is the reason that instructors produced results in line with it.

A limitation of the Pathfinder procedure is that it does not allow for labeling of links between the concepts. In traditional concept mapping, these links can also help elucidate the reasons why links are made. As such, they may help explain why a link was placed where it was. In the Pathfinder procedure, the thought process behind the ratings is not transparent. This is one of the tradeoffs for a procedure that can produce quantitative results for large numbers of students or instructors. 


\section{Suggestions for Future Research}

This research represents a preliminary examination of entering students' knowledge structures. It could be greatly expanded by both creating larger networks with more concepts and examining other areas of networking. It would also be interesting to gather networks from people working in the networking field full time to determine how similar their networks are to the instructors' network.

The most important outcome for most networking courses is whether students can actually configure, maintain, and troubleshoot networks. As such, the skill component to networking assessment is highly important. Future research should investigate the relationship between Pathfinder ratings and skills outcomes. This might take the form of developing a set of rating terms more appropriate to assess skills or correlating the conceptual knowledge ratings here to other skills assessments.

Another obvious extension of this research is to gather this data at various points during the course to track student progress and compare their changing conceptualizations to those of instructors. From an instructional standpoint, the teaching methods that result in lasting conceptual change are in need of considerably more investigation. While some strategies have been shown to be successful in reducing misconceptions, it has also been found that students sometimes continue to use the misconceptions in unfamiliar situations (Van Dooren, De Bock, Hessels, Janssens, \& Verschaffel, 2005) and will often return to the misconceptions after a period of time (Hellden \& Solomon, 2004). Interestingly, students may also be able to recognize correct explanations, but still exhibit misconceptions when asked to generate explanations (Kikas, 2003). What are the best ways to encourage students to question their existing ideas? Is directly addressing misconceptions a necessary component of changing them? These questions will be further explored in the next section.

\section{Classroom Application}

Theoretically, the process of changing conceptualizations can be described in terms of disequilibration, assimilation, and accommodation, as they were introduced by Piaget (1950). If the student can assimilate a new event into his/her existing conception, there will be no conceptual change. When students encounter an event or situation that does not fit into their current conceptualization, they enter a state of disequilibration. Students then must change their conceptions to fit this new event, a process called accommodation. Therefore, some have suggested that in order to effect conceptual change, students must be given events or situations which cannot fit into their current conceptualizations (Dykstra, 1992).

There has been research into techniques to move from students' initial conceptualizations to knowledge structures more like experts including having students make predictions and comparing them to outcomes of experiments (Khazanov, 2006), informing students about common misconceptions, either verbally or in text (Eryilmaz, 2002; Korner, 2005; Mikkila-Erdmann, 2001; Tekkaya, 2003; Uzuntiryaki \& Geban, 2005), use of analogies (Chiu \& Lin, 2005), and showing expert concept maps (Tekkaya, 2003; Uzuntiryaki \& Geban, 2005). .

In the results presented in this paper, many students exhibited a device-centric view of networking. If an instructor were to find this in their classroom, there are a variety of activities that could be undertaken to help students develop a more network-centric model. For example, students could engage in a classification task in which the teacher places signs with network types (this could be just LAN and WAN or expanded to Storage Area Networks, Virtual Private Networks, etc.) around the room. The students would then be given a pile of equipment (hubs, routers, switches, modems or at least pictures of such equipment) and asked to place them with the appropriate network type. Similarly, students could be given the equipment without categories and 
asked to develop categories by which it could be sorted. Classroom discussion should then follow as to what categories were selected and why, and a discussion of how "experts" would create categories.

The other finding from the Pathfinder analysis was that instructors organize their thinking about networks around the OSI model. This is important to develop in students because the OSI model also allows people to systematically troubleshoot network problems. For example, troubleshooting should begin at layer 1, the physical layer, by asking if all the network components are connected properly and plugged in. Once that is verified, the troubleshooter moves to layer 2. Understanding the OSI model happens over extended exposure to the ideas presented throughout a networking course. However, an important first step is to have students understand communication as something that can be thought of in layers. One way to introduce this idea is to have two students take walkie-talkies to different ends of the room and simulate a fast food drive through. The student playing the customer can violate various layers of the OSI model. For instance, the physical layer can be violated by not using the walkie-talkie; the transport layer can be violated by not waiting for the order to be repeated back before speaking. The presentation layer can be violated by having the student order in a different language. The student can violate that the application layer protocol by ordering pizza at a hamburger restaurant (Cisco Systems, 2004). As students begin to understand how communication can be explained in terms of layers, the way data networks communicate via these layers can be introduced.

Examples of successfully identifying and changing student misconceptions can be drawn from outside the field of computer networking. Uzuntiryaki \& Geban (2005) employed conceptual change text and concept maps to change students' conceptions of solutions in chemistry. Prior research had identified common solution misconceptions, such as the idea that during dissolution solute is absorbed by solvent and that dissolved solute has no volume. In order to attempt to change these conceptions, students first read texts that explicitly addressed the common misconceptions and either demonstrated why they were incorrect or used them as bridges to the correct understanding. It is thought that if students' initial ideas are not addressed in instruction, they may remain largely unchanged (Minstrell, 1989). The texts were specifically designed to create conceptual conflict. The students were then asked what happens when salt is added to water. As students tried to explain what happens, they were confronted with evidence that contradicted their assumptions. Finally, students were asked to construct concept maps with a predefined set of terms. In this case, bringing the maps into an instructional setting again allowed direct confrontation of students' misconceptions and explanations about why some links were appropriate and others were not. Finally, the misconceptions of students who went through the text and mapping exercises were compared with those who had not with the use of a test designed to reflect misconceptions and fundamental concepts. Students in the conceptual change condition performed significantly better on the test than those in the traditional instruction group, and also reported more positive attitudes toward the topic. This research serves to demonstrate the potential of directly confronting students' misconceptions and creating situations in which their current misconceptions are proven incorrect.

\section{References}

Anderson, D., Lucas, K. B., Ginns, I. S., \& Dierking, L. D. (2000). Development of knowledge about electricity and magnetism during a visit to a science museum and post-visit activities. Science Education, $84,658-679$.

Anderson, J. R. (1995). Cognitive psychology and its implications. New York: Freeman.

Ausubel, D. P. (1968). Educational psychology: A cognitive view. New York: Holt, Rinehart \& Winston. 
Bishop, B. A., \& Anderson, C. W. (1990). Student conceptions of natural selection and its role in evolution. Journal of Research in Science Teaching, 27, 415-427.

Borgen, K. L., \& Manu, S. S. (2002). What do students really understand? Journal of Mathematical Behavior, 21, 151-165.

Boo, H., \& Watson, J. R. (2001). Progression in high school students' (aged 16-18) conceptualizations about chemical reactions in solution. Science Education, 85, 568-585.

Bransford, J. D., Brown, A. L., \& Codking, R. (2000). How people learn: Brain, mind, experience, and school. Washington, D.C.: National Academies Press.

Braverman, E. P. (1997). Investigating the relationship between trainees' mental models and the transfer of training (Doctoral dissertation, University of Maryland College Park, 1997). Dissertation Abstracts International, 57, 10B, 6626.

Brown, J. S., \& Van Lehn, K. (1980). Repair theory: A generative theory of bugs in procedural skills. Cognitive Science, 4, 379-426.

Carpenter, T. P., Franke, M. L., Jacobs, V. R., Fennema, E., \& Empson, S. B. (1998). A longitudinal study of invention and understanding in children's multidigit addition and subtraction. Journal for Research in Mathematics Education, 29(1), 3-20.

Chen, C. (1997). Using similarity ratings and the Pathfinder algorithm for evaluating students' cognitive structures in Newtonian mechanics (Doctoral dissertation, The Ohio State University, 1997). Dissertation Abstracts International, 57, 7A, 2852.

Chiu, M., \& Lin, J. (2005). Promoting fourth graders' conceptual change of their understanding of electric current via multiple analogies. Journal of Research in Science Teaching, 42, 429-464.

Cisco Systems (2004). CCNA 1: Networking Basics v.3.1 Instructor Guide. San Jose, CA: Author.

Cobb, P., Wood, T., Yackel, E., Nicholls, J., Wheatley, G., Trigatti, B., \& Perlwitz, M. (1991). Assessment of a problem-centered second-grade mathematics project. Journal for Research in Mathematics Education, 22, 3-29.

Costu, B., \& Ayas, A. (2005). Evaporation in different liquids: Secondary students' conceptions. Research in Science \& Technological Education, 23, 75-97.

d'Apollonia, S., Charles, E., \& Boyd, G. (2004). Acquisition of complex systemic thinking: Mental models of evolution. Educational Research and Evaluation, 10, 499-521.

Davis, M. A., Curtis, M. B., \& Tschetter, J. D. (2003). Evaluating cognitive training outcomes: Validity and utility of structural knowledge assessment. Journal of Business and Psychology, 18, 191-206.

Dykstra, D. (1992). Studying conceptual change. In R. Duit, F. Goldberg \& H. Niedderer (Eds), Research in Physics Learning: Theoretical Issues and Empirical Studies (pp. 40-58). Kiel, Germany: Institute for Science Education at the University of Kiel.

Eryilmaz, A. (2002). Effects of conceptual assignments and conceptual change discussions on students' misconceptions and achievement regarding force and motion. Journal of Research in Science Teaching, 39, 1001-1015.

Geske, J. A. (2001). The structure of introductory statistics knowledge: An investigation exploring students' and experts' cognitive organization using multidimensional scaling and pathfinder analysis (Doctoral dissertation, University of Nebraska - Lincoln, 2001). Dissertation Abstracts International62, 3B, 1638.

Goldsmith, T. E., Johnson, P. J., \& Acton, W. H. (1991). Assessing structural knowledge. Journal of Educational Psychology, 83, 88-96.

Gomez, R. L., Hadfield, O. D., \& Housner, L. D. (1996). Conceptual maps and simulated teaching episodes as indicators of competence in teaching elementary mathematics. Journal of Educational Psychology, $88,572-585$. 
Gonzalvo, P., Canas, J. J., \& Bajo, M. (1994). Structural representations in knowledge acquisition. Journal of Educational Psychology, 86, 601-616.

Gouli, E., Gogoulou, A. \& Grigoriadou, M. (2003). A coherent and integrated framework using concept maps for various educational assessment functions. Journal of Information Technology Education, 2, 215-240. Retrieved May 10, 2007 from http://www.jite.org/documents/Vol2/v2p215-240-23.pdf

Guisasola, J., Almudi, J. M., \& Zubimendi, J. L. (2004). Difficulties in learning the introductory magnetic field theory in the first years of university. Science Education, 88, 443-464.

Halloun, I. A. \& Hestenes, D. (1985a). Common-sense concepts about motion. American Journal of Physics, 53, 1056-1065.

Halloun, I. A. \& Hestenes, D. (1985b). The initial knowledge state of college physics students. American Journal of Physics, 53, 1043.

Hayes-Roth, B., \& Thorndike, P.W. (1979). Integration of knowledge from text. Journal of Verbal Learning and Verbal Behavior, 18, 91-108.

Hellden, G. F., \& Solomon, J. (2004). The persistence of personal and social themes in context: Long- and short-term studies of students' scientific ideas. Science Education, 88, 885-900.

Hestenes, D., Wells, M., \& Swackhamer, G. (1992). Force Concept Inventory. The Physics Teacher, 30, 141-151.

Internet World Stats. (2006). World internet users and population stats. Retrieved January 4, 2007 from http://www.internetworldstats.com/stats.htm

Johnson, P. J., Goldsmith, T. E. \& Teague, K. W. (1994). Locus of the predictive advantage in Pathfinderbased representations of classroom knowledge. Journal of Educational Psychology, 86, 617-626.

Jonassen, J. H. \& Grabowski, B. L. (1993). Handbook of individual differences, learning and instruction. Part VII, Prior knowledge. Hillsdale, NJ: Lawrence Erlbaum Associates.

Kendeou, P., \& van den Broek, P. (2005). The effects of readers' misconceptions on comprehension of scientific text. Journal of Educational Psychology, 97, 235-245.

Khazanov, L. (2006). An investigation of approaches and strategies for resolving students' misconceptions about probability in introductory college statistics (Doctoral dissertation, Columbia University Teachers' College, 2006). Dissertation Abstracts International, 66, 10A, 3593.

Kikas, E. (2003). University students' conceptions of different physical phenomena. Journal of Adult Development, 10, 139-150.

Kinchin, I., Hay, D. B., \& Adams, A. (2000). How a qualitative approach to concept map analysis can be used to aid learning by illustrating patterns of conceptual development. Educational Research, 42, 4357.

Korner, C. (2005). Concepts and misconceptions in comprehension of hierarchical graphs. Learning and Instruction, 15, 281-296.

Kraiger, K., Ford, J. K., \& Salas, E. (1993). Application of cognitive, skill-based, and affective theories of learning outcomes to new methods of training evaluation. Journal of Applied Psychology, 78, 311-328.

Kudikyala, U. K., \& Vaughn, R. B. (2005). Software requirement understanding using Pathfinder networks: Discovering and evaluating mental models. Journal of Systems and Software, 74, 101-108.

Lim, B., \& Klein, K. J. (2006). Team mental models and team performance: A field study of the effects of team mental model similarity and accuracy. Journal of Organizational Behavior, 27, 403-418.

McClure, J., Sonak, B., \& Suen, H. (1999). Concept map assessment of classroom learning: Reliability, validity, and logistical practicality. Journal of Research in Science Teaching, 36, 475-492.

Michael, J. A. (1998). Students' misconceptions about perceived physiological responses. Advances in Physiology Education, 274, 90-98. 
Mikkila-Erdmann, M. (2001). Improving conceptual change concerning photosynthesis through text design. Learning and Instruction, 11, 241-257.

Minstrell, J. A. (1989). Teaching science for understanding. In L. Resnick \& L. Klopfer (Eds.), Toward the thinking curriculum: Current cognitive research (pp. 129-149). Alexandria, VA: Association for supervision and curriculum development.

Mogharreban, N. (2004). Approximate degrees of similarity between a user's knowledge and the tutorial systems' knowledge base. Journal of Information Technology Education, 3, 219-226. Retrieved May 10, 2007 from http://www.jite.org/documents/Vol3/v3p219-226-138.pdf

Novak, J. D. (1990). Concept mapping: A useful tool for science education. Journal of Research in Science Teaching, 27, 937-950.

Ober, B., \& Shenaut, G. K. (1999). Well-organized conceptual domains in Alzheimer's disease. Journal of the International Neuropsychological Society, 5, 676-684.

Odom, A. L., \& Barrow, L. H. (1995). Development and application of a two-tier diagnostic test measuring college biology students' understanding of diffusion and osmosis after a course of instruction. Journal of Research in Science Teaching, 32, 45-61.

Piaget, J. (1950). Psychology of intelligence. New York: Harcourt Brace.

Pine, K., Messer, D., \& St. John, K. (2001). Children's misconceptions in primary science: A survey of teachers' views. Research in Science \& Technological Education, 19, 79-96.

Resnick, L. (1987). Education and learning to think. Washington, D.C.: National Academy Press.

Rice, D., Ryan, J., \& Samson, S. (1998). Using concept maps to assess student learning in the science classroom: Must different methods compete? Journal of Research in Science Teaching, 35, 1103-1127.

Ruiz-Primo, M. A. \& Shavelson, R. J. (1996). Problems and issues in the use of concept maps in science assessment. Journal of Research in Science Teaching, 33, 569-600.

Schvaneveldt, R. W. (Ed.). (1990). Pathfinder Associative Networks: Studies in Knowledge Organization. Norwood, NJ: Ablex.

Schvaneveldt, R. W. (2007). Pathfinder 5.4. Tucson, AZ: Interlink.

Schvaneveldt, R. W., Beringer, D. B., \& Lamonica, J. A. (2001). Priority and organization of information accessed by pilots in various phases of flight. International Journal of Aviation Psychology, 11, 253280.

Sencar, S., \& Eryilmaz, A. (2004). Factors mediating the effect of gender on ninth-grade Turkish students' misconceptions concerning electric circuits. Journal of Research in Science Teaching, 41, 603-616.

Shaffer, D. M., \& McBeath, M. K. (2005). Naïve beliefs in baseball: systematic distortion in perceived time of apex for fly balls. Journal of Experimental Psychology: Learning, Memory, \& Cognition, 31, 14921501.

Taylor, A. K., \& Kowalski, P. (2004). Naïve psychological science: The prevalence, strength, and sources of misconceptions. Psychological Record, 54, 15-25.

Tekkaya, C. (2003). Remediating high school students' misconceptions concerning diffusion and osmosis through concept mapping and conceptual change text. Research in Science \& Technological Education, 21, 5-16.

Thornton, R. K., \& Sokoloff, D. R. (1998). Assessing student learning of Newton's laws, The Force and Motion Conceptual Evaluation and the evaluation of active learning laboratory and lecture curricula. American Journal of Physics, 66, 338-352.

Uzuntiryaki, E., \& Geban, O. (2005). Effect of conceptual change approach accompanied with concept mapping on understanding of solution concepts. Instructional Science, 33, 311-339. 
Van Dooren, W., De Bock, D., Hessels, A., Janssens, D., \& Verschaffel, L. (2005). Remedying secondary school students' illusion of linearity: Developing and evaluating a powerful learning environment. In. L. Verschaffel, E. De Corte, G. Kanselaar, \& M. Valcke (Eds.), Powerful environments for promoting deep conceptual and strategic learning (pp. 115-132). Leuven, Belgium, Leuven University Press.

Vosniadou, S., \& Brewer, W. F. (1992). Mental models of the earth: A study of conceptual change in childhood. Cognitive Psychology, 24, 535-585.

Walker, J. M. T., \& King, P. H. (2002). Concept mapping as a form of student assessment and instruction. Proceedings of the 2002 American Society for Engineering Education Annual Conference. Retrieved January 24, 2007 from http://www.vanth.org/docs/BMES 005.pdf

\section{Biography}

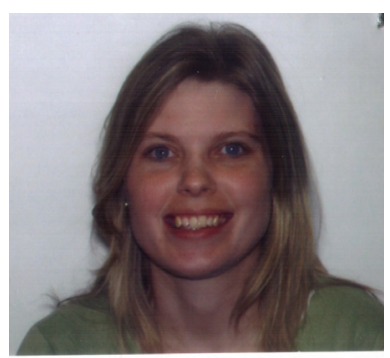

Kristen DiCerbo, Ph.D. is the Teaching and Learning Research Lead at Cisco Learning Institute. Her research interests include understanding how students learn computer networking, researching instructional practice around the world, and using new and different techniques to explore teaching and learning. Cisco Learning Institute is a nonprofit organization committed to innovation through integrating technology and evaluation into education. This includes conducting research and evaluation of the Cisco Networking Academy Program. 